\title{
Effect of Experimental Escherichia coli Meningitis on Concentrations of Excitatory and Inhibitory Amino Acids in the Rabbit Brain: In Vivo Microdialysis Study ${ }^{1}$
}

\author{
VICTOR L. PERRY, RICHARD S. K. YOUNG, WILLIAM J. AQUILA. \\ AND MATTHEW J. DURING \\ Departments of Pediatrics /I .L.P., R.S.K.Y., W.J.A.J. Neurosurgery [M.J.D.J, and Neurology /R.S.K.Y.J. \\ Yale University School of Medicine, New Haven. Connecticut 06510
}

\begin{abstract}
Excessive extracellular fluid concentrations of the amino acids glutamate and aspartate play an important role in the pathogenesis of neuronal cell damage during hypoxia, hypoglycemia, and seizure. The purpose of these investigations was to test the hypothesis that bacterial meningitis causes progressive increase in excessive extracellular fluid concentrations of excitatory and inhibitory neurotransmitters. To test this hypothesis, Escherichia coli was injected intracisternally in juvenile rabbits after which neurotransmitter concentrations were measured with in vivo microdialysis. The data showed significant elevation of the excitatory amino acids aspartate and glutamate, as well as of the inhibitory neurotransmitters $\boldsymbol{\gamma}$-amino butyric acid and taurine in the excessive extracellular fluid of animals injected with $E$. coli compared with control animals injected with saline. However, concentrations of these excitatory and inhibitory amino acids rose late in the course of meningitis, at a time when the animals were hypotensive (mean blood pressure $\leq 40 \mathrm{~mm} \mathrm{Hg}$ ). These data show that the major increase in excitatory neurotransmitters during experimental meningitis occurs in association with the cerebral ischemia produced by septic shock rather than being produced by the meningitis itself. (Pediatr Res 34: 187-191, 1993)
\end{abstract}

Abbreviations

GABA, $\gamma$-amino butyric acid

ECF, extracellular fluid

NMDA, $N$-methyl-D-aspartate

CSF, cerebrospinal fluid

CBF, cerebral blood flow

A large body of in vivo and in vitro experiments already support the notion that excessive concentrations of the excitatory amino acids glutamate and aspartate are an integral link in the chain of events leading to neuronal death (1-4) in a variety of brain insults including ischemia (5-7), hypoglycemia (8), complex seizure (9), and trauma (10). Excessive cell excitation by glutamate or aspartate opens receptor (NMDA) operated calcium channels, allowing neurons to accumulate toxic concentrations

Received July 9. 1992: accepted March 9.1993.

Correspondence: Richard S. K. Young, M.D.. Department of Pediatrics, Hospital of St. Raphael, 1450 Chapel St.. New Haven. CT 06511.

Supported in part by NIH Grants NS RO1.24605 (R.S.K.Y.) and NS-28227 (M.J.D.).

Presented in part at the Child Neurology Society, Portland. OR. October 1991 of intracellular calcium (1, 2, 11). Further evidence for the "excitotoxic" theory is provided by experiments that show that antagonists to NMDA can prevent cerebral ischemic injury (1214).

Recently, several investigators proposed that the excitatory amino acids glutamate and aspartate are involved in the pathogenesis of brain injury in bacterial meningitis (15-17). Preliminary experiments by Tunkel et al. (18) show that concentrations of glutamate increase substantially in the CSF of rabbits exposed to endotoxin, pneumococcal cell walls, or live pseudomonads. Despite the enthusiasm to include meningitis in the list of brain disorders caused by "excitotoxins," other factors that may play an etiologic role in brain damage in meningitis must be considered; $e . g$. alterations in CBF. Studies of human infants and monkeys and rabbits show reductions in $\mathrm{CBF}$ or cerebral blood velocity during bacterial meningitis (19). Cerebral perfusion may be impaired during bacterial meningitis as a consequence of vasculitis, impaired autoregulation (19), or hypotension.

The aim of the present investigations was to test the hypothesis that excessive accumulation of excitatory amino acids occurs during acute bacterial meningitis. To accomplish this, we used cerebral microdialysis, a versatile tool that allows the determination of dynamic changes in concentrations of amino acids in the extracellular space. Through systemic physiologic and metabolic measurements, we hoped also to clarify the relationship of the rise in excitatory amino acids to changes in blood pressure, arterial $\mathrm{pH}$, and blood glucose and lactate. Developing animals were studied because meningitis occurs most frequently in the young human.

\section{MATERIALS AND METHODS}

Animal preparation. Juvenile (20- to 30 -d-old, mean wt $892 \mathrm{~g}$ ) New Zealand White rabbits were anesthetized with halothane (induction, 4\%: maintenance, $1 \%$ ) and tracheotomized. An arterial catheter was inserted to monitor blood pressure and blood gases. All sites of incision were initially infiltrated with lidocaine $(1 \%)$ followed by application of topical lidocaine.

After tracheostomy and arterial catheterization, halothane was discontinued, and the animals were mechanically ventilated (Harvard rodent ventilator; Harvard Apparatus, So. Natick, MA) with a gas mixture containing $70 \% \mathrm{~N}_{2} \mathrm{O} / 30 \% \mathrm{O}_{2}\left(\mathrm{~N}_{2} \mathrm{O}\right.$ induces an amnestic state). The animals were paralyzed with pancuronium $(0.5 \mathrm{~mL} / \mathrm{h})$ to prevent dislodgement of intracerebral and intracisternal catheters (see below). The ventilator was adjusted to ensure normoxia [arterial oxygen tension $>100 \mathrm{~mm} \mathrm{Hg}(>13.3$ $\mathrm{kPa})$ ] and normocarbia [arterial carbon dioxide tension, 30-40 $\mathrm{mm} \mathrm{Hg}(4.0-5.3 \mathrm{kPa})]$. Blood glucose and blood lactate were monitored with a Beckman Glucose Analyzer II (Beckman In- 
struments, Palo Alto, CA) and Yellow Springs Lactate Analyzer (Yellow Springs Instruments, Yellow Springs, $\mathrm{OH}$ ), respectively. Because neuromuscular blockade was used, body temperature was maintained at $36^{\circ} \mathrm{C}$ by means of a rectal probe and servocontrolled heating unit (Yellow Springs Instruments). The electroencephalogram was recorded with subdermal electrodes and a Grass model 79D polygraphic recorder (Grass Instruments, Quincy, MA).

Studies were approved by the Yale Animal Care and Use Committee and were performed in accordance with federal guidelines for the care and use of laboratory animals.

In vivo cerebral microdialysis. Microdialysis probes of a concentric design were fabricated from vitreous silica fibers (Polymicro Technologies, Phoenix, AZ) arranged side by side and inserted into a dialysis sack $(300-\mu \mathrm{m}$ outside diameter Caprophan, 5000-kD cutoff; 4-mm exposed membrane surface; Fig. 1) (20). This design reduced the probe dimensions, minimized brain trauma, and minimized the dead space between the dialyzed brain area and the sampling tube. The microdialysis probe was stereotactically lowered into the posterior frontal cerebral cortex (coordinates from the bregma: $3 \mathrm{~mm}$ posterior, $2 \mathrm{~mm}$ lateral, and $4 \mathrm{~mm}$ inferior to the skull surface) according to the atlas of Urban and Richard (21). Probe location was verified visually post-mortem. No samples were obtained for $2.5 \mathrm{~h}$ after probe

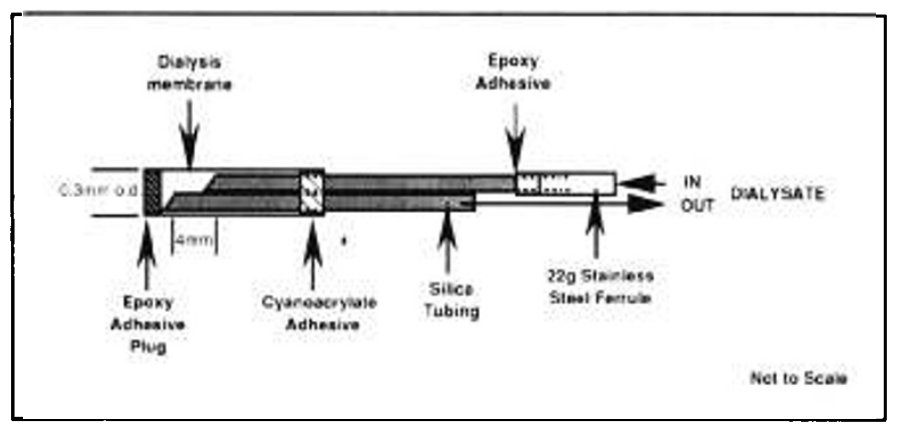

Fig. 1. Microdialysis probe. The probe consists of a pair of vitreous silica fibers mounted in a dialysis membrane. Molecules, driven by a concentration gradient, cross the dialysis membrane.

$$
\begin{array}{ll}
\text { A. Normai } & \text { B. Slow }
\end{array}
$$
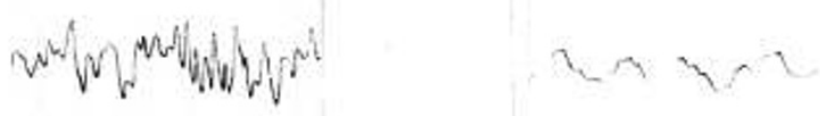

c. Attenusted

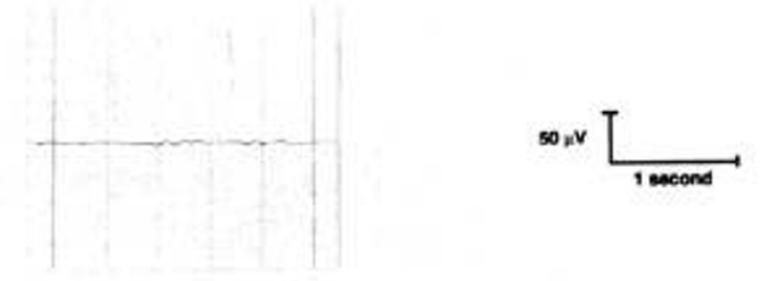

Fig. 2. EEG changes in experimental meningitis. EEG activity was characterized as normal $(A)$, slow $(B)$, or attenuated $(C)$. During the baseline period, EEG activity consisted of asynchronous $5-$ to $10-\mathrm{Hz}$ activity $(A)$. Within $2 \mathrm{~h}$ of administration of $E$. coli, there was substantial slowing of background rhythms $(B)$ followed by progressive attenuation (C). placement to avoid traumatic artifacts. Previous studies have confirmed that the presence of the probe does not cause significant changes in amino acid levels in ECF 2 to $3 \mathrm{~h}$ after probe placement.

The dialysate was delivered through the probe at $2 \mu \mathrm{L} / \mathrm{min}$ with a microinfusion pump (Harvard Apparatus). The ionic composition of the dialysate consisted of $147 \mathrm{mM} \mathrm{Na}^{+}, 129 \mathrm{mM}$ $\mathrm{Cl}^{-}, 1.2 \mathrm{mM} \mathrm{Ca}^{++}, 3.5 \mathrm{mM} \mathrm{K}^{+}, 1.0 \mathrm{mM} \mathrm{Mg}^{++}, 1 \mathrm{mM}$ phosphate, and $25 \mathrm{mM} \mathrm{HCO}_{3}{ }^{-}$at $\mathrm{pH} \mathrm{7.4}$. Probe efficiency was determined by placing probes in $10^{-6}$ and $10^{-7} \mathrm{M}$ solutions of amino acids. Recovery of amino acids ranged from 20 to $30 \%$. Collected samples were frozen and later analyzed with a BAS-200A Ternary Gradient HPLC system (Bioanalytical Systems Inc., W. Lafayette, IN) with a CM-200 autoinjector. The amino acids were derivatized using the autoinjector before injection. The derivatizing reagent consisted of $100 \mathrm{mg}$ of O-phthaldehyde in $2.5 \mathrm{~mL}$ methanol, $2.5 \mathrm{~mL} 0.2 \mathrm{M}$ borate buffer, $\mathrm{pH} 9.6$, with $22.5 \mu \mathrm{L}$ of tert-butylthiol. An 8:1 sample to reagent ratio was used. After a 60 -s reaction, the samples were injected into the BAS $200 \mathrm{HPLC}$ using a BAS phase $2100 \times 3.2 \mathrm{~mm} 3-\mu \mathrm{m}$ outside diameter column. The mobile phase used to achieve separation was $0.1 \mathrm{M}$ acetic acid, $\mathrm{pH} 5.8$, with an increasing gradient of acetonitrile from 12 to $30 \%$ and tetrahydrofuran from 1.2 to $15 \%$.

Chromatograms were usually complete within $16 \mathrm{~min}$ with separation of the major transmitter amino acids. Combination dual electrochemical, 600-mV (detector 1) and 700-mV (detector 2) versus an $\mathrm{Ag} / \mathrm{AgCl}$ reference electrode [and $\mathrm{UV}$ (330-nm) detectors in series in selected samples] were used with peak heights recorded on a two-channel chart recorder and compared with standards. We determined the concentrations of the excitatory amino acids glutamate and aspartate and the inhibitory amino acids GABA, glycine, and taurine. Alanine was measured because concentrations of this amino acid rise during impaired oxidative metabolism $(6,9,22)$.

Bacteriology and cisternal cannulation. E. coli, originally isolated from a clinical specimen (courtesy of Col. Alan Cross, Walter Reed Army Medical Center), was grown in flasks of trypticase soy broth at $37^{\circ} \mathrm{C}$ to a concentration of $10^{6}$ organisms/ $\mathrm{mL}$. The organisms were then centrifuged, washed, and resuspended in saline. The actual titer of the innoculum was determined by quantitative cultures on blood agar plates.

The model of experimental meningitis in rabbits described by Dacey and Sande (23) was used in these studies. The skin overlying the cisternal space was shaved and scrubbed with povidine iodine. The posterior atlantooccipital membrane was then exposed through sharp dissection, and a 22-gauge stainless steel cannula was stereotactically lowered through the membrane to obtain CSF.

Preliminary studies were conducted in pentobarbital-anesthetized, but not paralyzed, rabbits to determine the size of inoculum needed to produce meningitis. These studies disclosed that intracisternal injection of $10^{6} \mathrm{E}$. coli organisms produced opisthotonos, pupillary dilatation, and coma after 1 to $2 \mathrm{~h}(25)$.

Experimental protocol. After insertion of the microdialysis probe, a 2 -h period was allowed for probe equilibration and prevention of traumatic artifacts. After this equilibration period, baseline measurements of blood pressure, $\mathrm{pH}, \mathrm{PCO}_{2}, \mathrm{PO}_{2}$, glucose, and lactate were made. A sample of CSF was obtained, and concentrations of glucose and lactate were measured. An aliquot of dialysate was obtained from the microdialysis probe to determine ECF concentrations of excitatory and inhibitory amino acids.

The animals were then randomized to a control group or to the experimental (meningitis) group. Animals in the former group were injected intracisternally with $0.3 \mathrm{~mL}$ of sterile normal saline (control animals), whereas those in the latter group received $10^{6} \mathrm{E}$. coli organisms suspended in $0.3 \mathrm{~mL}$ of saline. Samples of arterial blood, CSF, and dialysate were then obtained hourly for $6 \mathrm{~h}$ in the control animals, after which the control animals were killed with a bolus of pentobarbital $(50 \mathrm{mg} / \mathrm{kg})$ and 

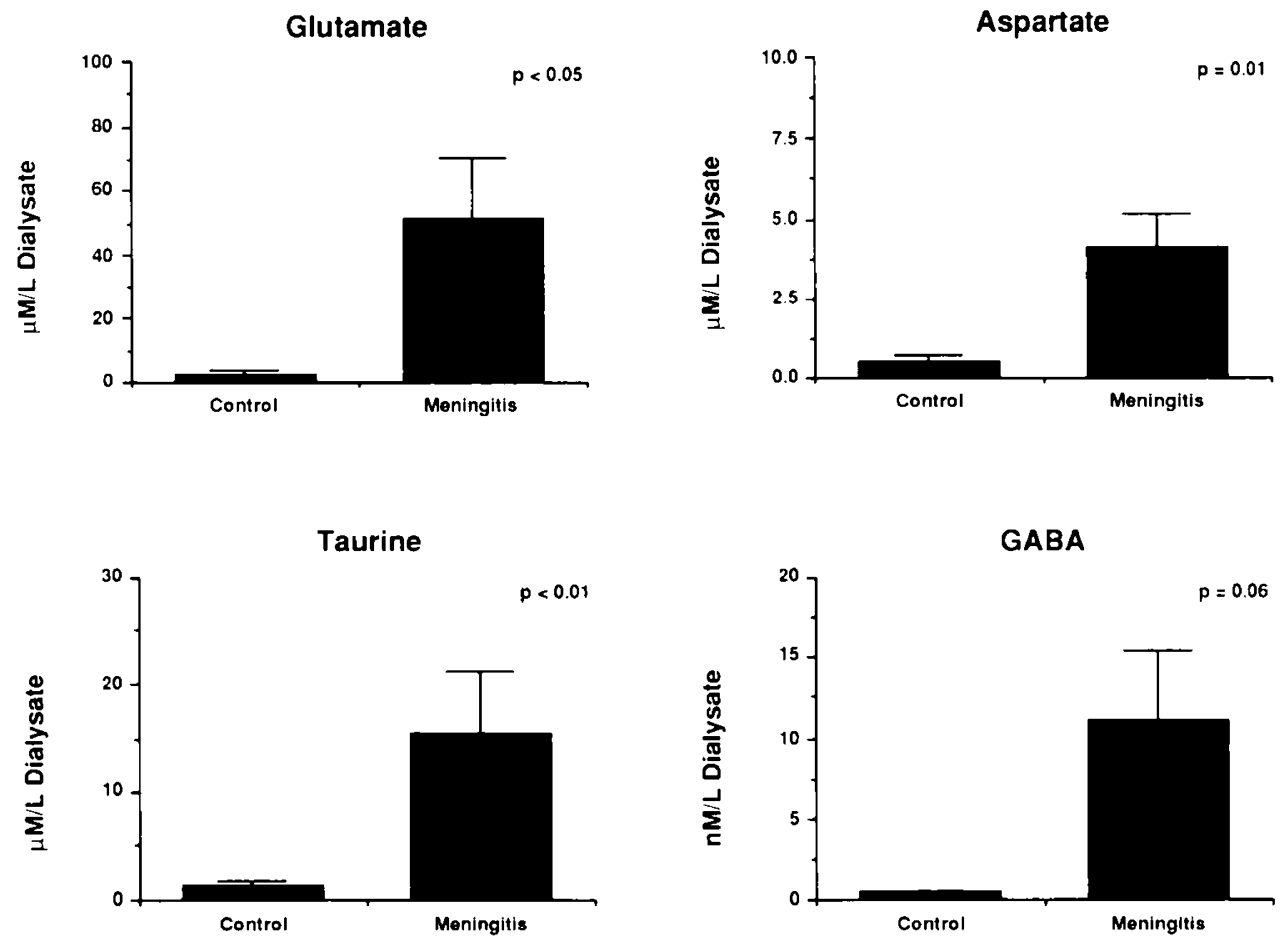

Fig. 3. Excitatory and inhibitory neurotransmitters in experimental meningitis. Concentrations of the excitatory amino acids, glutamate and aspartate $(\mu \mathrm{mol} / \mathrm{L}$ dialysate), and inhibitory amino acid, taurine, were significantly elevated after $6 \mathrm{~h}$ of $E$. coli meningitis compared with salinetreated control animals. The rise in GABA (nmol/L dialysate) in meningitic animals was nearly significant; $n=10$ (controls, 4; meningitis, 6 ); statistical analysis by $t$ test.

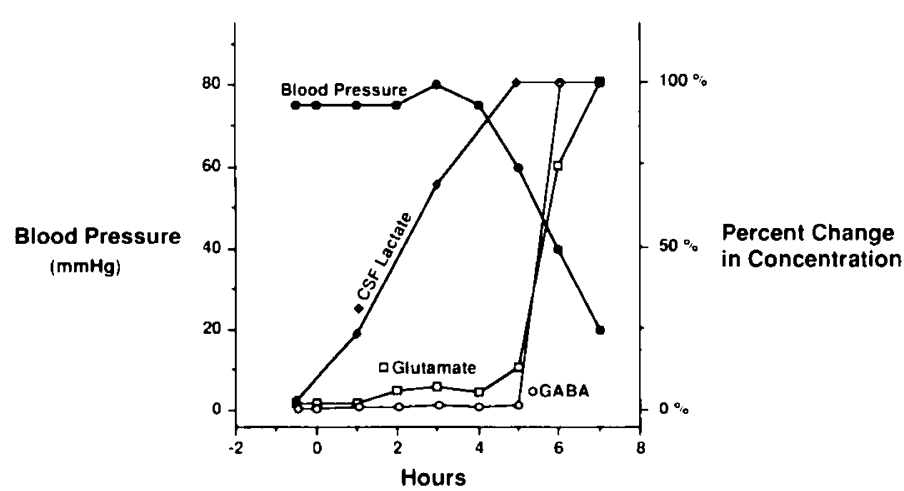

Fig. 4. Inverse relationship between rise in glutamate and decline in blood pressure in experimental meningitis. Blood pressure is stable for the first $4 \mathrm{~h}$ of meningitis. As the blood pressure begins to fail, there is a rise in concentrations of the brain's principal excitatory amino acid, glutamate, and inhibitory amino acid, GABA. Elevation of these amino acids is greatest when blood pressure falls below the lower end of the autoregulatory plateau. Note that CSF lactate, an indicator of meningitis, rises well in advance of the increase in glutamate.

$\mathrm{KCl}(2 \mathrm{cc})$. Animals subjected to meningitis were observed until they died or became profoundly hypotensive (blood pressure $<20$ $\mathrm{mm} \mathrm{Hg}$ ). After death, the brain was removed, fixed in $10 \%$ formalin, embedded in paraffin, sectioned, and examined by light microscopy.

Statistical analysis. A total of 10 animals were studied (four control animals, six experimental animals). Values are reported as mean \pm SEM. Measurements of excitatory and inhibitory amino acids, plasma and CSF glucose and lactate, and blood pressure in control and experimental animals were analyzed with the two-tailed $t$ test (24). Values were deemed significant at $p<$ 0.05 .

\section{RESULTS}

Systemic, CSF, and EEG measurements. Control animals showed no significant alteration of blood pressure, plasma glu- cose or lactate, or CSF glucose or lactate during any of the six hourly measurements. The EEG in these animals showed moderate voltage $(<200 \mu \mathrm{V}), 8$ to $10 \mathrm{~Hz}$ activity.

In contrast, animals subjected to experimental $E$. coli meningitis developed significant hypotension after $6 \mathrm{~h}$ (controls, $68 \pm$ $9 \mathrm{~mm} \mathrm{Hg}$; meningitis, $21 \pm 5 ; p<0.0001, t$ test). The duration of survival for meningitic animals was $6.3 \pm 0.8 \mathrm{~h}$. Blood glucose after $6 \mathrm{~h}$ was $3.78 \pm 0.56 \mathrm{mM}$ in control animals and $3.28 \pm$ 0.56 in meningitic animals. Blood lactate was $0.37 \pm 0.08 \mathrm{mM}$ in control animals after $6 \mathrm{~h}$ versus $1.83 \pm 0.64 \mathrm{mM}$ in animals subjected to meningitis. However, at the end of the period of observation, CSF glucose was $25 \%$ lower (at $6 \mathrm{~h}$ : controls, 4.83 $\pm 0.94 \mathrm{mM}$; meningitis, $3.67 \pm 0.39$ ), and CSF lactate was 4-fold greater in the meningitic animals (controls, $1.4 \pm 0.67$ $\mathrm{mM}$; meningitis, $5.4 \pm 1.7 ; p=0.05$ ). Examination of the EEG showed substantial slowing of background rhythms (Fig. 2) within $2 \mathrm{~h}$ of injection of $E$. coli. Thereafter, the electrical activity became severely attenuated.

Microdialysis measurements. Control animals showed no significant alteration in concentrations of glutamate, aspartate, GABA, glycine, taurine, or alanine during the $6 \mathrm{~h}$ of observation. In contrast, there was significant increase in the excitatory amino acids glutamate and aspartate and in the inhibitory amino acids GABA and taurine in animals exposed to $E$. coli meningitis (Fig. 3 ). After $6 \mathrm{~h}$, concentrations of alanine and glycine were also increased in animals subjected to meningitis compared with control animals (alanine: control, $2.5 \pm 0.63 \mu \mathrm{M} / \mathrm{L} ;$ meningitis, $13.57 \pm 2.65 ; \mathrm{p}<0.01 ;$ glycine, control, $5.36 \pm 1.08 ;$ meningitis, $18.4 \pm 2.74 ; p<0.01)$. There was an inverse rise in glutamate and GABA and decline in blood pressure in animals subjected to experimental meningitis (Fig. 4).

Neuropathology. Neuropathologic examination showed widespread accumulation of polymorphonuclear leukocytes in the Virchow-Robin space of the cortex of animals injected with $E$. coli.

\section{DISCUSSION}

The most striking finding in this study was the marked increase in concentrations of both excitatory and inhibitory amino acids 
in the animals subjected to $E$. coli meningitis compared with control animals. However, careful inspection of the time course of the rise in glutamate in experimental meningitis and the decline in blood pressure showed an inverse relationship with abrupt increase in these amino acids when the blood pressure fell below $40 \mathrm{~mm} \mathrm{Hg}$. It is at this point that the animal's cerebral perfusion would likely fail and ischemia occurs. CBF fell to negligible levels $(<20 \mathrm{~mL} / 100 \mathrm{~g} / \mathrm{min})$ when blood pressure was $<45 \mathrm{~mm} \mathrm{Hg}$ in rabbits subjected to pneumococcal meningitis (26). Our laboratory previously demonstrated that CBF falls regardless of whether hypotension is caused by hemorrhage or by $E$. coli endotoxin (27). Experiments to demonstrate that hypotension induced by $E$. coli endotoxin will cause similar alterations in levels of extracellular neurotransmitters are in progress.

Focal or global cerebral ischemia frequently complicates bacterial meningitis for a number of reasons: impaired cerebral autoregulation, septic shock due to bacteria or bacterial cell products, vasculitis due to inflammation in the Virchow-Robin space, and polymorphonuclear leukocyte obstruction of the microcirculation (28).

The magnitude of the rise in excitatory and inhibitory amino acids in our experimental animals was consistent with that observed by other investigators in studies of cerebral ischemia. Ten min of ischemia in fetal sheep induced by cord compression produced marked increase in glutamate (maximum, 11-fold), aspartate (maximum, 7-fold), GABA (maximum, 5-fold), and taurine (maximum, 18-fold) in cerebral cortex (5). Marked increase in glutamate and aspartate (8- and 3-fold, respectively) was noted in the hippocampus of adult rats during $10 \mathrm{~min}$ of complete transient cerebral ischemia (6). Alanine levels were also severely increased in the meningitic animals. Alanine production increases by transamination of pyruvate formed during increased glycolysis. An increase in alanine was also observed in rabbits that became hypotensive during seizure (28).

Could the delayed rise in glutamate and GABA be attributable to the fact that meningitis developed only after many hours? This is an unlikely explanation, inasmuch as the animals became symptomatic from meningitis hours before the rise in glutamate and GABA. Our preliminary studies in nonparalyzed animals disclosed the development of opisthotonos and coma within $1 \mathrm{~h}$ after injection of bacteria. In addition, the rise in CSF lactate and slowing of EEG activity preceded the rise in excitatory and inhibitory neurotransmitters. These data suggest that if there is increased release of excitatory neurotransmitters during the early phase of meningitis, concomitant mechanisms for removal exist such that no net accumulation occurs in the ECF.

Could the development of seizure activity play a role in the rise in excitatory and inhibitory amino acids in meningitis? This is not a tenable explanation, because studies in our laboratory show that uncomplicated seizures (no preceding hypoxia or hypotension) do not produce alterations of excitatory or inhibitory amino acids. Other investigators have also demonstrated that neither bicuculine- nor kainic acid-induced seizure produces an increase in glutamate or GABA $(22,29)$. From this, we conclude that in meningitis, as with seizure, as long as CBF and levels of ATP are maintained (3), any increase in levels of excitatory amino acids is counterbalanced by uptake.

A similar parallel may be drawn between rise in excitatory neurotransmitters during hypoxia and hypoglycemia. Hypoxia that is too brief to cause a decrease in ATP levels does not result in a significant increase in glutamate. Similarly, glutamate does not increase during hypoglycemia until blood glucose falls below $1.1 \mathrm{mM}(8)$.

In summary, there is excessive accumulation of excitatory and inhibitory amino acids in bacterial meningitis. However, the stimulus triggering the release of glutamate and aspartate may be the hypotension of septic shock rather than bacterial infection itself. This finding is consistent with the clinical observation that hypotension during meningitis is a poor prognostic sign.

Acknowledgments. The authors thank Drs. Robert Baltimore and Vincent Quagliarello for helpful advice.

\section{REFERENCES}

1. Choi DW 1990 Cerebral hypoxia: some new approaches and unanswered questions. J Neurosci 10:2493-2501

2. Rothman SM. Olney JW 1986 Glutamate and the pathophysiology of hypoxicischemic brain damage. Ann Neurol 19:105-111

3. Young RSK, Petroff OAC, Novotny Jr EJ, Wong M 1990 Neonatal excitotoxic brain injury: physiologic, metabolic, and pathologic findings. Dev Neurosci 12:210-220

4. Young RSK, Petroff OAC, Aquila WJ, Yates J 1991 Effects of glutamate, quisqualate, and $N$-methyl-D-aspartate in neonatal brain. Exp Neurol 111:362-368

5. Hagberg H. Andersson P. Kjellmer I. Thiringer K. Thordstein M 1987 Extracellular overflow of glutamate, aspartate, GABA and taurine in the cortex and basal ganglia of fetal lambs during hypoxia-ischemia. Neurosci Lett 78:311-317

6. Benveniste H, Drejer J. Schousboe A. Diemer NH 1984 Elevation of the extracellular concentrations of glutamate and aspartate in rat hippocampus during transient cerebral ischemia monitored by intracerebral microdialysis. J Neurochem 43:1369-1 374

7. Globus MY-T, Busto R. Martinez E, Valdés I, Dietrich WD, Ginsberg MD 1991 Comparative effect of transient global ischemia on extracellular levels of glutamate, glycine, and $\gamma$-amino butyric acid in vulnerable and nonvulnerable brain regions in the rat. J Neurochem 57:470-478

8. Silverstein FS, Simpson J, Gordon KE 1990 Hypoglycemia alters striatal amino acid efflux in perinatal rats: an in vivo microdialysis study. Ann Neurol 28:516-521

9. Young RSK, During MJ, Aquila WJ, Tendler D. Ley E 1992 Hypoxia increases extracellular concentrations of excitatory and inhibitory neurotransmitters in subsequently induced seizure: in vivo microdialysis study in the rabbit. Exp Neurol 117:204-209

10. Faden AI, Demediuk P. Panter SS, Vink R 1989 The role of excitatory amino acids and NMDA receptors in traumatic brain injury. Science 244:798-800

11. Simon RP 1989 Role of endogenous excitatory amino acid neurotransmitters in the pathogenesis and evolution of acute brain injury. Pediatr Infect Dis $J$ 8:913-914

12. Hattori H, Morin AM, Schwartz PH, Fujikawa DG, Wasterlain CG 1989 Posthypoxic treatment with MK-801 reduces hypoxic-ischemic damage in the neonatal rat. Neurology 39:713-718

13. McDonald JW, Silverstein FS, Johnston MV 1988 Neurotoxicity of $N$-methylD-aspartate is markedly enhanced in developing rat central nervous system. Brain Res 459:200-203

14. Park CK, Nehls DG. Graham DI. Teasdale GM. McCulloch J 1988 The glutamate antagonist MK-801 reduces focal ischemic brain damage in the rat. Ann Neurol 24:543-551

15. Täuber MG, Borschberg U, Sande MA 1988 Influence of granulocytes on brain edema, intracranial pressure, and cerebrospinal fluid concentrations of lactate and protein in experimental meningitis. J Infect Dis 157:456-464

16. Sande MA. Täuber MG. Scheld WM. McCracken Jr GH 1989 Pathophysiology of bacterial meningitis: summary of the workshop. Pediatr Infect Dis J 8:929-933

17. Sáez-Llorens X, Ramilo O. Mahmoud MM, Mertsola J, McCracken Jr GH 1990 Molecular pathophysiology of bacterial meningitis: current concepts and therapeutic implications. J Pediatr 116:671-684

18. Tunkel AR, Demediuk P, Khayam-Bashi H 1989 Excitatory amino acids in experimental meningitis. 29th Interscience Conference on Antimicrobial Agents and Chemotherapy, Houston. TX. September 1989(abstr 713)

19. Tureen JH, Dworkin RJ, Kennedy SL, Sachdeva M. Sande MA 1990 Loss of cerebrovascular autoregulation in experimental meningitis in rabbits. J Clin Invest 85:577-581

20. During MJ, Heyes MP, Freese A. Markey SP, Martin JB, Roth RH 1989 Quinolinic acid concentrations in striatal extracellular fluid reach potentially neurotoxic levels following systemic L-tryptophan loading. Brain Res 476:384-387

21. Urban I, Richard P 1972 A Stereotaxic Atlas of the New Zealand Rabbit's Brain. Thomas, Springfield

22. Lehmann A, Hagberg H, Jacobson 1, Hamberger A 1985 Effects of status epilepticus on extracellular amino acids in the hippocampus. Brain Res 359:147-151 
23. Dacey RG. Sande MA 1974 Effect of probenecid on cerebrospinal fluid concentrations of penicillin and cephalosporin derivatives. Antimicrob Agents Chemother 6:437-441

24. Quagliarello VJ, Long WJ, Scheld WM 1986 Morphologic alterations of the blood-brain barrier with experimental meningitis in the rat. J Clin Invest 77:1084-1095

25. Abacus Concepts Inc 1986 Statview $512^{+}$. Brainpower Inc, Calabasas

26. Tureen JH, Stella FB, Clyman RI, Mauray F, Sande MA 1987 Effect of indomethacin on brain water content, cerebrospinal fluid white blood cell response, and prostaglandin $E_{2}$ levels in cerebrospinal fluid in experimental pneumococcal meningitis in rabbits. Pediatr Infect Dis J 6:1151-1153

27. Young RSK, Yagel SK, Towfighi J 1983 Systemic and neuropathologic effects of $E$. coli endotoxin in neonatal dogs. Pediatr Res 17:349-353

28. Grøgaard B, Schürer L. Gerdin B, Arfors KE 1989 Delayed hypoperfusion after incomplete forebrain ischemia in the rat. The role of polymorphonuclear leukocytes. J Cereb Blood Flow Metab 9:500-505

29. Lehmann A. Isaacson $H$. Hamberger A 1983 Effects of in vivo administration of kainic acid on the extracellular amino acid pool in the rabbit hippocampus. J Neurochem 40:1314-1320

\section{Announcement}

\section{Charles E. Culpeper Foundation Scholarships in Medical Science}

The Charles E. Culpeper Foundation is currently accepting applications for its 1994 Scholarships in Medical Science Program designed to support the career development of academic physicians.

Up to three awards of $\$ 100,000$ per year for 3 years will be made to United States medical schools on behalf of candidates who are U.S. citizens, who have received their M.D. degree from a U.S. medical school in 1985 or later, and who are judged worthy of support by virtue of the quality of their research proposals. All scientific research relevant to human health is eligible for consideration. No institution may nominate more than one candidate.

In selecting awardees, emphasis will be on identifying young physicians with clear potential for making substantial contributions to science as academic physicians. Since January 1988,18 physicians have been selected as Charles E. Culpeper Foundation Medical Scholars.

Deadline for applications is August 16,1993. Awards will be announced by January 14, 1994 for activation on or about July 1, 1994. Application forms and instructions may be obtained by contacting the Charles $\mathrm{E}$. Culpeper Foundation at Financial Centre, 695 East Main Street. Suite 404. Stamford. CT 06901. 